\title{
Postoperative self-report of pain in children: Interscale agreement, response to analgesic, and preference for a faces scale and a visual analogue scale
}

\author{
Clément de Tovar MD ${ }^{1}$, Carl L von Baeyer $\mathrm{PhD}^{2}$, Chantal Wood $\mathrm{MD}^{3}$, Jean-Pierre Alibeu MD ${ }^{4}$,
} Malik Houfani MD ${ }^{3}$, Charles Arvieux MD PhD ${ }^{1}$

C de Tovar, CL von Baeyer, C Wood, J-P Alibeu, M Houfani, C Arvieux. Postoperative self-report of pain in children: Interscale agreement, response to analgesic, and preference for a faces scale and a visual analogue scale. Pain Res Manage 2010;15(3):163168.

OBJECTIVE: To augment available validation data for the Faces Pain Scale - Revised (FPS-R) and to assess interscale agreement and preference in comparison with the Coloured Analogue Scale (CAS) in pediatric acute pain.

METHOD: The present prospective, multicentre study included 131 inpatients five to 15 years of age (mean age 8.8 years; $56 \%$ male) seen in postoperative recovery. They provided CAS and FPS-R pain scores before and after administration of analgesic medication. Nurses and physicians used the same tools as observational scales. Children and health care providers indicated which scale they preferred.

RESULTS: FPS-R scores for the intensity of postoperative pain correlated highly with the corresponding CAS scores in all age groups $(0.66 \leq r \leq 0.88)$. There were no significant mean differences in any age group between the scales. Scores on the two scales differed by $2 / 10$ or less in $81 \%$ to $91 \%$ of children, depending on age. Both scales demonstrated expected changes in postoperative pain following administration of an analgesic. Scores at the upper end point were given by approximately $20 \%$ of children five to six years of age on both scales, compared with $2 \%$ to $9 \%$ in the older age groups. Health care providers' observational ratings were significantly lower than self-ratings. The FPS-R was preferred over the CAS by most children in all age groups and both sexes. Global satisfaction of the health care providers was similar for both tools.

DISCUSSION: These results support the use of the FPS-R for most children five years of age or older in the postoperative period. Further research is needed to identify young children, particularly those younger than seven years of age, who have difficulty with self-report tools, and to establish methods for training them in the reliable use of these measures.

Key Words: Children; Faces Pain Scale - Revised; Measurement; Pediatric pain; Self-report; Visual analogue scale

\section{L'auto-évaluation de la douleur postopératoire chez les enfants : concordance entre échelles, réponse aux antalgiques, et préférence pour une échelle des visages et une échelle visuelle analogique}

OBJECTIF : Augmenter les données de validation disponibles pour l'échelle Faces Pain Scale - Revised (FPS-R), évaluer la concordance entre les échelles et la préférence par rapport à une échelle analogique colorée (Coloured Analogue Scale [CAS]) lors de douleurs aigues chez l'enfant.

METHODOLOGIE : Cette étude prospective multicentrique a inclus 131 patients hospitalisés âgés de cinq à 15 ans (moyenne 8,8 ans; $56 \%$ de garçons) vus en salle de surveillance post-interventionelle. Ils ont évalué leur douleur avec le CAS et la FPS-R avant et après l'administration d'antalgiques. Les infirmières et les médecins ont utilisé les mêmes échelles comme outils d'hétéro-évaluation. Les enfants et les soignants ont indiqué quelle échelle ils préféraient.

RÉSULTATS : Les scores de douleur postopératoire obtenus par la FPS-R étaient fortement corrélés avec les scores obtenus par la CAS dans tous les groupes d'âge $(0,66 \leq \mathrm{r} \leq 0,88)$. On ne remarquait pas de différence significative entre les échelles selon le groupe d'âge. Les différences de scores obtenus par ces deux échelles étaient de 2/10 ou moins chez $81 \%$ à $91 \%$ des enfants en fonction de leur âge. Les deux échelles montraient des modifications attendues après l'administration d'un antalgique. Environ $20 \%$ des enfants de cinq à six ans donnaient un score correspondant aux valeurs supérieures sur les deux échelles par rapport à $2 \%$ à $9 \%$ dans les groupes des enfants plus âgés. Les scores d'hétéro-évaluation des soignants ont été sensiblement inférieurs à ceux obtenus par l'auto-évaluation. La FPS-R a été préférée au CAS par la plupart des enfants quel que soit leur âge ou leur sexe. La satisfaction globale des soignants a été similaire pour les deux outils.

DISCUSSION : Ces résultats plaident en faveur de l'utilisation de la FPS-R pour la plupart des enfants âgés de cinq ans ou plus en période postopératoire. Des recherches supplémentaires sont nécessaires pour identifier les jeunes enfants, en particulier ceux au-dessous de sept ans, qui ont des difficultés à s'auto-évaluer, et pour trouver des méthodes pour les former à mieux utiliser ces échelles.

with some other faces scales (5-7). The FPS-R and instructions for its administration in many languages are available at www.painsourcebook.ca.

Hicks et al (3) suggest that further studies be conducted to compare the FPS-R with other self-report scales in larger clinical samples. It is particularly important to assess the utility of the FPS-R with children younger than seven years of age. At this stage in their cognitive development, children may have
Self-report measures of pain intensity for children have been discussed in recent reviews $(1,2)$. Among the tools recommended on the basis of utility and validity is the Faces Pain Scale - Revised (FPS-R) (3), a scale that was adapted from the earlier Faces Pain Scale (4) to make it compatible with the widely accepted 0 to 10 metric. An advantage of the FPS-R is that it does not include a smiling face or tears, thus avoiding the confounding of pain with affect that may occur

${ }^{1}$ Department of Anaesthesiology, CHU Cavale Blanche, Brest, France; ${ }^{2}$ Departments of Psychology and Pediatrics, University of Saskatchewan, Saskatoon, Saskatchewan; ${ }^{3}$ Pain Unit, CHU Robert Debré, Paris; ${ }^{4}$ Pain Center, CHU Michallon, Grenoble, France

Correspondence: Dr Carl L von Baeyer, Department of Psychology, University of Saskatchewan, 9 Campus Drive, Saskatoon,

Saskatchewan S7N 5A5. Telephone 306-966-6676, fax 306-966-6630, e-mail carl.vonbaeyer@usask.ca 
difficulty focusing on more than one dimension of a target at a time, which may contribute to their reported overuse of the end points of scales compared with values closer to the scale mean (3,8-10). In other words, many young children appear to treat a pain scale as dichotomous rather than graded. This observation would suggest that screening and training in the use of self-report scales might be needed for young children (11), and that further study of pain measurement is needed in this age group.

The FPS-R was compared with another self-assessment instrument, the Coloured Analogue Scale (CAS; 12), for the present study. The CAS was selected because it was widely available at the time of data collection, had excellent supporting evidence (12) and was based on the 0 to 10 metric, which is preferred for pediatric pain scales (3). In a replication and extension of the methods of Hicks et al (3), the following hypotheses were tested as a contribution to validation of the pain measures for children five to 15 years of age: that responses on two pain scales, the FPS-R and the CAS (12), would be in strong agreement with each other; that self-reports and health care providers' reports of pain would be moderately correlated with each other, and that the observational scores would be lower than self-report scores; that FPS-R scores would show significant reductions following administration of analgesia; that younger children would select extreme scores more often, and would show lower interscale agreement than older children; and that the FPS-R would be preferred over the CAS, particularly by younger children.

The goal of the present study was to assess the validity of the FPS- $\mathrm{R}$ in a postoperative pediatric population and to assess scale preference and interscale agreement with the CAS. The methods of Hicks et al (3) were extended by including a larger sample (131 versus a visual analogue scale [VAS] and a CAS group of 45 children each); including adolescents up to 15 years rather than 12 years of age; using the French-language versions of the respective pain scales; asking for present rather than remembered worst pain, thus including children who reported no pain, unlike the clinical study of Hicks et al in which ratings of $0 / 10$ were absent; and collecting data in the recovery room, thus gaining more immediate information about postoperative pain.

\section{Setting and participants}

\section{METHOD}

The present study was carried out over a four-month period in the pediatric surgical services of three urban hospitals in France. Following institutional ethics approval and with the consent of their parents, children between five and 15 years of age were invited during consultation with the anesthesiologist to participate in a study of the assessment of postoperative pain. No patients declined to participate. Consent was obtained from 131 children ( 74 boys and 57 girls) with a mean ( \pm SD) age of $8.8 \pm 3.1$ years. Groups formed for age comparisons were as follows: five to six years (mean 5.7 years, $n=47$ ), seven to 10 years (mean 8.9 years, $n=49$ ) and 11 to 15 years (mean 13.0 years, $n=35)$. Age groups in developmental studies are deliberately formed to allow smaller age ranges at periods of more rapid change. Data were gathered by one physician in each hospital (a resident, a fellow and a senior consultant in anesthesia) and nurses. Data were gathered by nurses in
74 cases and by physicians in 57 cases; no other information regarding the nurses was collected.

The reason for hospitalization was surgical treatment in all cases, including ear/nose/throat (63\%), orthopedic (14\%), abdominal (9\%), urological (3\%) and other (11\%).

\section{Materials}

Coloured Analogue Scale: The CAS (12) is an adaptation of a VAS that consists of a mechanical device with a plastic slider over a $143 \mathrm{~mm}$ long tetragon varying from narrow $(10 \mathrm{~mm})$ and white at the end labelled 'no pain' to wide $(30 \mathrm{~mm})$ and dark red at the end labelled 'most pain' (in French). Each child who was assigned to use the CAS was asked to move the slider to the position that reflected his or her current pain. The CAS was scored from 0 to 10 in increments of 0.25 .

Faces Pain Scale - Revised: The FPS-R (www.painsourcebook.ca) (3) was printed on a plastic card for the present study, $24 \mathrm{~cm} \times$ $5 \mathrm{~cm}$, showing six black and white line drawings of faces. Each face was $25 \mathrm{~mm} \times 35 \mathrm{~mm}$, with $13 \mathrm{~mm}$ between the faces. Each child was asked to point to the face that best reflected his or her current pain. The end points were explained as 'no pain' and 'very much pain' (in French). The FPS-R was scored from 0 to 10 in increments of 2 .

The two pain scales were not introduced to the child before their surgery; only two children indicated familiarity with the FPS-R and eight with the CAS before data collection in the recovery room.

\section{Procedure}

After surgery, patients were taken to the recovery room. When they were sufficiently alert to respond verbally, a nurse or physician gave standard instructions for the two scales. The children were asked to self-rate their pain using the FPS-R and the CAS. The order of administration of the scales was recorded; $57 \%$ received the FPS-R first, and $43 \%$ received the CAS first, at the discretion of the nurse or physician administering the scales. Analgesic medication was then provided when needed; 67 children $(51 \%)$ received analgesics, of which 91\% were intravenous opioids. Approximately $5 \mathrm{~min}$ to $15 \mathrm{~min}$ later, a second self-rating was collected using the FPS-R and the CAS in the same order as previously administered. The second pair of ratings was collected from $56 \%$ of the total sample. Children who completed both pairs of ratings had significantly higher pain scores on the first rating $\left(t_{122}=7.5, \mathrm{P}<0.001\right)$ than children who completed only the first pair of ratings. In the former group, only $3 \%$ gave a score of 0 on the FPS-R, while $45 \%$ of the latter group did so. This indicates that children who were comfortable were likely to leave the recovery room sooner and were less likely to be asked for a second set of pain ratings.

Observational ratings were recorded by a nurse or physician before each self-rating using the same two scales, the FPS-R and the CAS. Thus, staff were blind to children's self-report for the first but not the second rating. Finally, before each child was returned to the ward, the child and nurse or physician separately completed a questionnaire asking about the ease of use of the two scales and their preference among the two.

\section{Analysis}

Both parametric and nonparametric statistical approaches were used. Pain scores may not meet all assumptions for parametric analysis, in particular, due to the occurrence of a greater 


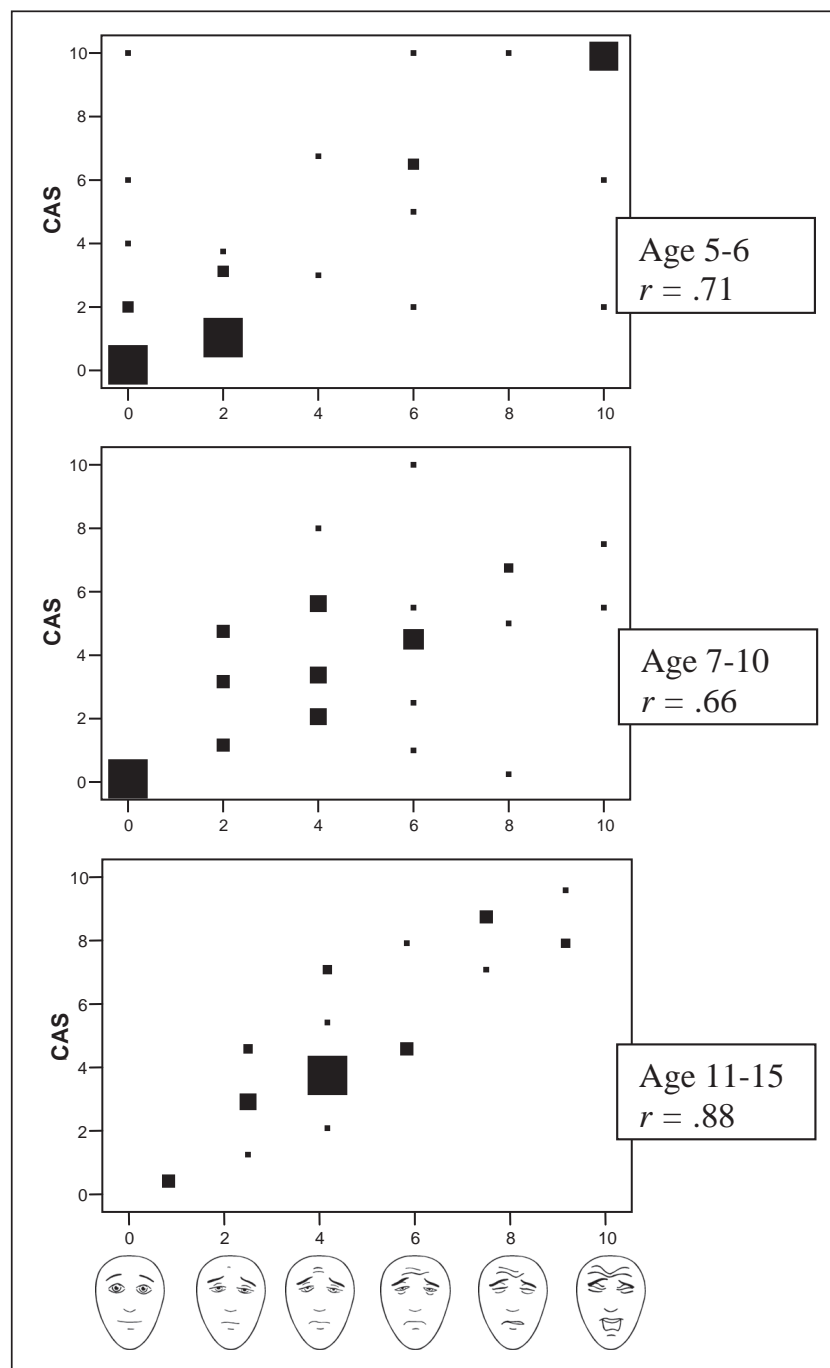

Faces Pain Scale - Revised

Figure 1) Scatter plots and correlations of self-ratings on the Coloured Analogue Scale (CAS) and the Faces Pain Scale Revised by age group (in years). Larger boxes indicate larger numbers of patients. The Faces Pain Scale - Revised is reproduced with permission; copyright 2001, International Association for the Study of Pain (also at www.painsourcebook.ca)

number of extreme scores ( 0 and 10$)$ than would be expected in a normal distribution. However, it is very common to report means, SDs, correlations and other parametric values for pain scales, so these are provided for comparison with earlier reports. In addition, raw scatter plots and analyses of proportions are provided because these require no parametric assumptions. For analyses of concordance between the self-report and observational scores, only the first pairs of ratings were used to ensure that staff were blind to the self-report scores.

\section{RESULTS}

Interscale agreement and effects of age

For the total sample, the correlation between FPS-R and CAS scores was $r=0.73$. For the youngest, middle and oldest age groups, the correlations between CAS and FPS-R scores were $\mathrm{r}=0.71, \mathrm{r}=0.66$ and $\mathrm{r}=0.88$, respectively. Figure 1 shows scatter
TABLE 1

Pain scores by age group

\begin{tabular}{llcccc}
\hline & & \multicolumn{3}{c}{ Age group, years } & \\
\cline { 2 - 5 } Scale (range) & & $\mathbf{5 - 6}$ & $\mathbf{7 - 1 0}$ & $\mathbf{1 1 - 1 5}$ & Total \\
\hline CAS (0-10) & Mean \pm SD & $4.0 \pm 3.7$ & $3.3 \pm 2.5$ & $4.7 \pm 2.6$ & $3.9 \pm 3.0$ \\
& Median & 3.0 & 3.3 & 4.5 & 3.8 \\
& IQR & $1.0-6.9$ & $1.0-5.0$ & $3.5-7.0$ & $1.3-6.0$ \\
& $\% \geq 4 / 10$ & 40.5 & 44.7 & 62.9 & 48.7 \\
FPS-R (0-10) & Mean \pm SD & $3.7 \pm 3.8$ & $3.7 \pm 2.8$ & $4.5 \pm 2.7$ & $3.9 \pm 3.1$ \\
& Median & 2.0 & 4.0 & 4.0 & 4.0 \\
& IQR & $0-6$ & $2-6$ & $2-6$ & $2-6$ \\
& $\% \geq 4 / 10$ & 42.9 & 59.6 & 71.4 & 57.3 \\
\hline
\end{tabular}

$\% \geq 4 / 10$ denotes the percentage of patients with pain scored at $4 / 10$ or greater. CAS Coloured Analogue Scale; FPS-R Faces Pain Scale - Revised; IQR Interquartile range (showing 25th and 75 th percentiles)

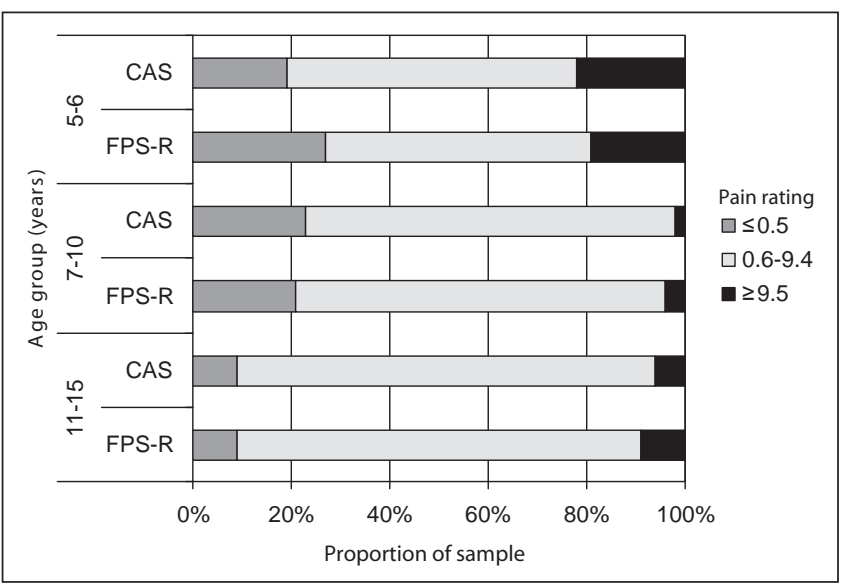

Figure 2) End point bias for the Coloured Analogue Scale (CAS) and the Faces Pain Scale - Revised (FPS-R) by age group. Percentages of scores are at the top and bottom ends of the scale. For FPS-R, end point percentages are shown for scores 0 and 10; for CAS, percentages are shown for scores in the top and bottom $5 \%$ of the scale range

plots of the relationship between CAS and FPS-R scores for the three age groups separately.

The correlation between CAS and FPS-R scores could be inflated by use of the extremes. To check for such an artifact, children who scored $10 / 10$ on either scale were removed and the correlations were recalculated. The number of children dropped for this analysis was nine for the youngest age group and three for each of the two older age groups. Without these scores, the correlation for the five- to six-year-old age group dropped from $r=0.71$ to $r=0.60(n=27)$. The corresponding correlations for the middle and oldest age group were unaffected by this adjustment because few scores of 10 were recorded in the latter groups.

\section{Distribution of self-ratings of pain intensity}

Table 1 shows the means, SDs, medians and interquartile ranges of pain self-rating scores on the CAS and FPS-R. The two scale means for the total group were identical. There were no significant differences in the mean scores for the two scales in any age group. There were no significant differences between age groups on either scale.

Figure 2 shows the proportion of children in each age group who scored their pain at either the top or bottom extreme of 
TABLE 2

Comparison of pain ratings by self-report and observational rating

\begin{tabular}{lcc}
\hline & Self-rating & Observational rating \\
\hline CAS $(n=119)$ & $3.9 \pm 3.0$ & $2.7 \pm 2.4$ \\
FPS-R $(n=124)$ & $4.0 \pm 3.2$ & $2.5 \pm 2.6$ \\
\hline
\end{tabular}

Data presented as mean \pm SD. End points for both scales are 0 and 10. CAS

Coloured Analogue Scale; FPS-R Faces Pain Scale - Revised

\section{TABLE 3}

Coloured Analogue Scale (CAS) and Faces Pain Scale Revised (FPS-R) ratings before and after analgesia

\begin{tabular}{lcc}
\hline & CAS (0-10), $\mathbf{n = 6 6}$ & FPS-R (0-10), $\mathbf{n = 6 9}$ \\
\hline Before analgesia & $5.5 \pm 2.5$ & $5.6 \pm 2.7$ \\
After analgesia & $2.6 \pm 2.3$ & $2.5 \pm 2.3$ \\
\hline
\end{tabular}

Data presented as mean $\pm S D$. Change before and after analgesia is significant $(P<0.05)$ for both scales

the scale. As expected, the youngest age group was most likely to use the score 10/10 on both scales.

As another index of children's comprehension of the selfrating task, the proportion of children who provided discordant scores on the CAS and FPS-R was calculated, ie, scores differing by more than $2 / 10$ between the two scales. This twopoint difference is the minimum difference that can be meaningfully detected using the FPS-R because of its two-point scaling interval; it also approximates the difference in scores identified for pediatric pain scales as much better or much worse (13). For the youngest, middle and oldest age groups, the proportion of children who gave ratings differing by more than $2 / 10$ on the FPS-R and CAS was $19 \%, 17 \%$ and $9 \%$, respectively.

\section{Order of administration}

The order of administration of the two scales had no significant effect on mean self-ratings (between-groups $t=0.51, \mathrm{P}=0.61$ ).

The correlation between the FPS- $\mathrm{R}$ and the CAS was $r=0.78$ when the FPS- $R$ was administered first, and $r=0.65$ when the CAS was administered first. Those two correlations were not statistically significantly different.

\section{Comparison of self-ratings and observational ratings}

Means and SDs of pain scores recorded by self-rating and observational rating are shown in Table 2 . The health care providers' mean scores were significantly lower than the children's self-ratings on the CAS (paired $t=4.9, \mathrm{P}<0.001$ ) and on the FPS-R (paired $t=6.7, \mathrm{P}<0.001$ ).

For the following nonparametric analysis, scores of $6 / 10$ or greater were classified as 'high pain' on both self-report and observational forms of the VAS and FPS-R scales. On the FPS-R, 42 children gave self-reports of high pain, and of these, $24(57 \%)$ were given scores below $6 / 10$ on the observational FPS-R. On the VAS, 42 children gave self-reports of high pain, and of these, $27(64 \%)$ were given scores below $6 / 10$ on the observational VAS. Conversely, only five children (6\%) who rated their pain as lower than $6 / 10$ on each measure were assigned high observational pain scores by staff.

The correlations between the observational and self-report pain scores were $r=0.55$ for the CAS and $r=0.66$ for the FPS-R.
TABLE 4

Children who prefer the Faces Pain Scale - Revised (FPS-R) versus the Coloured Analogue Scale (CAS) by age group and sex

\begin{tabular}{|c|c|c|c|c|c|}
\hline $\begin{array}{l}\text { Age group } \\
\text { (years) or sex }\end{array}$ & $\begin{array}{l}\text { Prefer } \\
\text { CAS }\end{array}$ & $\begin{array}{l}\text { Prefer } \\
\text { FPS-R }\end{array}$ & $\begin{array}{c}\text { No } \\
\text { preference }\end{array}$ & $\begin{array}{c}\text { Don't know or } \\
\text { no response }\end{array}$ & Total \\
\hline $5-6, n=47$ & 17.0 & 55.3 & 8.5 & 19.1 & 100 \\
\hline $7-10, n=49$ & 22.4 & 51.0 & 12.2 & 14.2 & 100 \\
\hline $11-15, n=35$ & 28.6 & 51.4 & 14.3 & 5.7 & 100 \\
\hline Boys, n=74 & 24.3 & 51.4 & 12.2 & 12.2 & 100 \\
\hline Girls, n=57 & 19.3 & 54.4 & 10.5 & 15.8 & 100 \\
\hline Total, n=131 & 22.1 & 52.7 & 11.5 & 13.8 & 100 \\
\hline
\end{tabular}

Data presented as percentages

\section{Response to analgesic}

Table 3 shows mean self-rated pain scores before and after administration of analgesic medication. As expected, pain was significantly reduced on both scales following medication (paired $t=8.0$ and $t=8.5$ for the FPS-R and the CAS, respectively; $\mathrm{P}<0.0001$ ). Interpretation of this finding is subject to the caution that it was a selected sample; children who were comfortable at the time of the first rating did not receive extra analgesic and were not as likely to be asked for a second pair of pain ratings (see Procedure).

Preference of scale among children, nurses and physicians Table 4 shows the percentage of children who preferred the FPS-R versus the CAS by age group and sex. The FPS-R was significantly preferred over the CAS; $70 \%$ of children who expressed a preference for one scale preferred the FPS-R $\left(\chi^{2}=16.3, \mathrm{df}=1, \mathrm{P}<0.001\right)$. Preference was not associated with demographic characteristics of the children (Kendall's $\tau_{b}<0.14$, $\mathrm{P}>0.14$ for both age and sex).

Ratings were collected by nurses and physicians who were asked for their preference of the FPS-R versus the CAS for each case. Among the nurses, for $23 \%$ of cases, no preference was expressed; for 38\%, the FPS-R was preferred; and for 39\%, the CAS was preferred. Among the physicians, no preference was expressed for $42 \%$ of cases, the FPS-R was preferred in 39\% of cases and the CAS was preferred in 19\% of cases. Overall, there were no statistically significant differences in preference for one tool over the other among the health care providers.

\section{DISCUSSION}

The goal of the present study was to increase knowledge of the validity and utility of the FPS-R by extending the methods of Hicks et al $(2,3)$.

The tendency of more children in the youngest age group than in older age groups to endorse the upper extreme score, $10 / 10$, was confirmed, as previously observed $(3,8-10,14)$. In the present sample, approximately $20 \%$ of the five- and six-year-olds chose the upper extreme of the two scales. Two explanations for this phenomenon seem plausible in the present context. First, the youngest age group may, in fact, have had a larger proportion of children with unrelieved severe pain than the other age groups. Eighty per cent of the five- and six-year-olds had undergone ear/nose/throat surgery with no subsequent intravenous analgesia, in contrast with the older children, who all received opioid analgesia. Second, the youngest children were more challenged by the cognitive complexity of estimating their own pain and matching it to values on a 
pain scale; they might have a greater tendency to simplify the task by choosing the extremes of the scales.

Using a larger sample, we confirmed a finding of Hicks et al the correlations of scores on the CAS and FPS-R were similar in all age groups, implying that the stage of cognitive development had little influence overall on understanding and use of the pain scales. However, children in the youngest age group selected more extreme scores (10/10), as found in previous studies, suggesting that efforts to screen them for understanding of the scales may be merited.

The present study was different from that of Hicks et al in several respects. The present study was carried out in the recovery room (where some confusion might linger even in awake children) rather than on the ward. However, there was no significant difference in the number of children who needed to have the instructions repeated among children who were awake compared with those who had to be woken up. The interscale concordance reported by Hicks et al could have been inflated by their inclusion of remembered pain (for those children who had no pain at the time of data collection) rather than just currently experienced pain. There could have been variations between studies in the instructions. In the present study, the scales were administered by several different nurses and physicians, whereas in the study by Hicks et al, all data were collected personally from the children by only two researchers, who were presumably more consistent in their administration from one child to the next.

The order of administration had no significant effect on the mean pain score. When the FPS- $\mathrm{R}$ was given first, the correlation between the two scales $(r=0.78)$ exceeded a common and conventional cut-off for validity coefficients $(0.70)$; when the CAS was given first, the correlation did not meet that criterion $(\mathrm{r}=0.65)$. The results support the proposition that it may have been somewhat easier for children to understand the initial explanation of pain estimation using the FPS-R than the CAS.

Important limitations of the present study include the failure to collect information on the nurses who collected data for the study, and the fact that the order of presentation of the two self-report scales was left to the discretion of the physician or nurse rather than being properly randomized.

The present study confirmed previous results $(15,16)$ showing that children's postoperative pain is commonly underestimated by adults in comparison with self-reports, regardless of the scale used. Illustrating this difference, nurses

\section{REFERENCES}

1. Stinson JN, Kavanagh T, Yamada J, Gill N, Stevens B. Systematic review of the psychometric properties, interpretability and feasibility of self-report pain intensity measures for use in clinical trials in children and adolescents. Pain 2006;125:143-57.

2. von Baeyer CL. Children's self-reports of pain intensity: Scale selection, limitations and interpretation. Pain Res Manage 2006;11:157-62.

3. Hicks CL, von Baeyer CL, Spafford PA, van Korlaar I, Goodenough B. The Faces Pain Scale-Revised: Toward a common metric in pediatric pain measurement. Pain 2001;93:173-83.

4. Bieri D, Reeve RA, Champion GD, Addicoat L, Ziegler JB. The Faces Pain Scale for the self-assessment of the severity of pain experienced by children: Development, initial validation, and preliminary investigation for ratio scale properties. Pain 1990;41:139-50.

5. Chambers CT, Craig KD. An intrusive impact of anchors in children's faces pain scales. Pain 1998;78:27-37. and physicians in the present study assigned observational ratings of less than $6 / 10$ to approximately $60 \%$ of children who reported their own pain at $6 / 10$ or greater. On the other hand, pain was 'overestimated' by staff in only $6 \%$ of patients.

According to Champion et al (6), "the ideal unidimensional scale for measuring pain intensity should... be sensitive to changes in pain intensity." The present results show the expected significant reductions in self-report pain scores on both scales following administration of an analgesic.

One objective of the present study was to determine the preference for pain scales among children and health care providers. Preference for a scale is related to ease of use in clinical and research settings, and may contribute to the validity of a scale independent of its psychometric properties. West et al (17) showed that the Faces Pain Scale (4) was preferred to the Poker Chip Tool. The present study demonstrates that, regardless of age and sex, the FPS-R is preferred to the CAS by most children. Indices of health care providers' satisfaction and preference were similar for the two instruments. The FPS-R has the advantage of being available online free of charge and readily replaced using photocopies, while the CAS, which is a nonreplaceable plastic tool, is now very difficult to obtain commercially and may need to be sterilized.

\section{CONCLUSION}

These results, extending previous research, provide further support for the use of the FPS-R as a self-report pain scale for most children five years of age and older. The FPS-R is well accepted and understood by most children, and is preferred to the CAS in all age groups. Scores correspond closely with those from the CAS and show the expected reduction following analgesic medication. Further research is needed to identify young children, particularly those younger than seven years of age, who have difficulty with self-report tools (11), and to establish methods for training them in the reliable use of self-report pain measures.

AUTHOR NOTE: The present report is based on an MD thesis in Anesthesiology and Intensive Care by C de Tovar at the Université de Brest (Brest, France) under the supervision of $\mathrm{C}$ Arvieux. The research was previously presented in two posters for the 10th World Congress on Pain, from August 17 to 22, 2002 in San Diego, California (USA). The authors appreciate suggestions on an earlier version provided by Tiina Jaaniste. 
11. Besenski LJ, Forsyth SJ, von Baeyer CL. Screening young children for their ability to use self-report pain scales. Pediatr Pain Lett 2007;9:1-6.

12. McGrath PA, Seifert CE, Speechley KN, Booth JC, Stitt L, Gibson MC. A new analogue scale for assessing children's pain: An initial validation study. Pain 1996;64:435-43.

13. Powell CV, Kelly AM, Williams A. Determining the minimum clinically significant difference in visual analog pain score for children. Ann Emerg Med 2001;37:28-31.

14. Goodenough B, Thomas W, Champion GD, et al. Unravelling age effects and sex differences in needle pain: Ratings of sensory intensity and unpleasantness of venipuncture pain by children and their parents. Pain 1999;80:179-90.

15. Chambers CT, Reid GJ, Craig KD, McGrath PJ, Finley GA. Agreement between child and parent reports of pain. Clin J Pain 1998;14:336-42.

16. Romsing J, Moller-Sonnergaard J, Hertel S, Rasmussen M. Postoperative pain in children: Comparison between ratings of children and nurses. J Pain Symptom Manage 1996;11:42-6.

17. West N, Oakes L, Hinds PS, et al. Measuring pain in pediatric oncology ICU patients. J Pediatr Oncol Nurs 1994;11:64-8. 


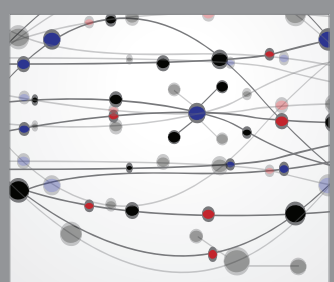

The Scientific World Journal
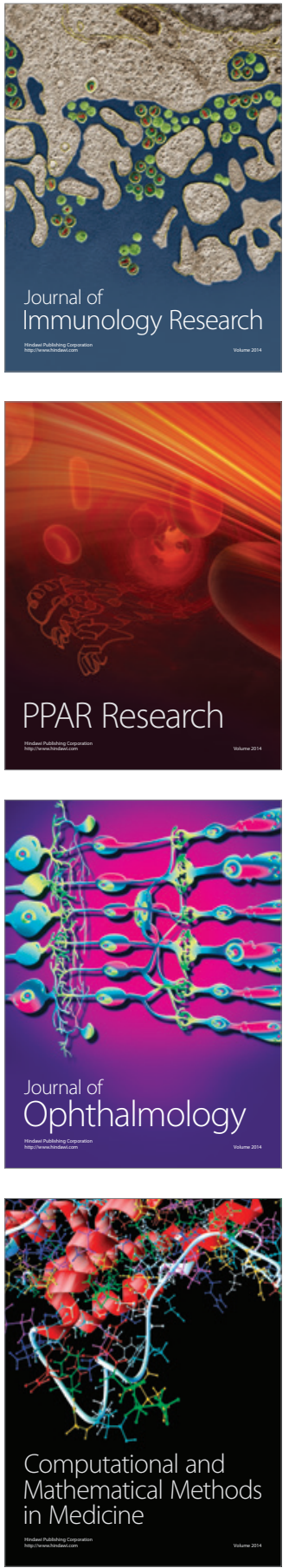

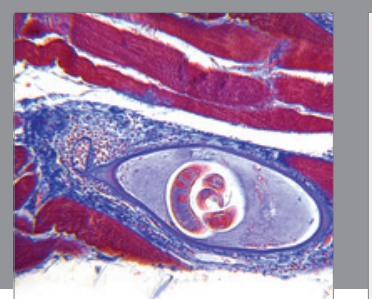

Gastroenterology Research and Practice

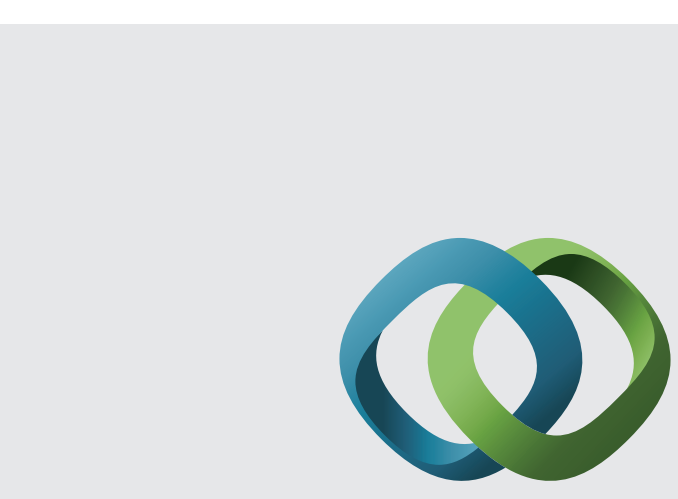

\section{Hindawi}

Submit your manuscripts at

http://www.hindawi.com
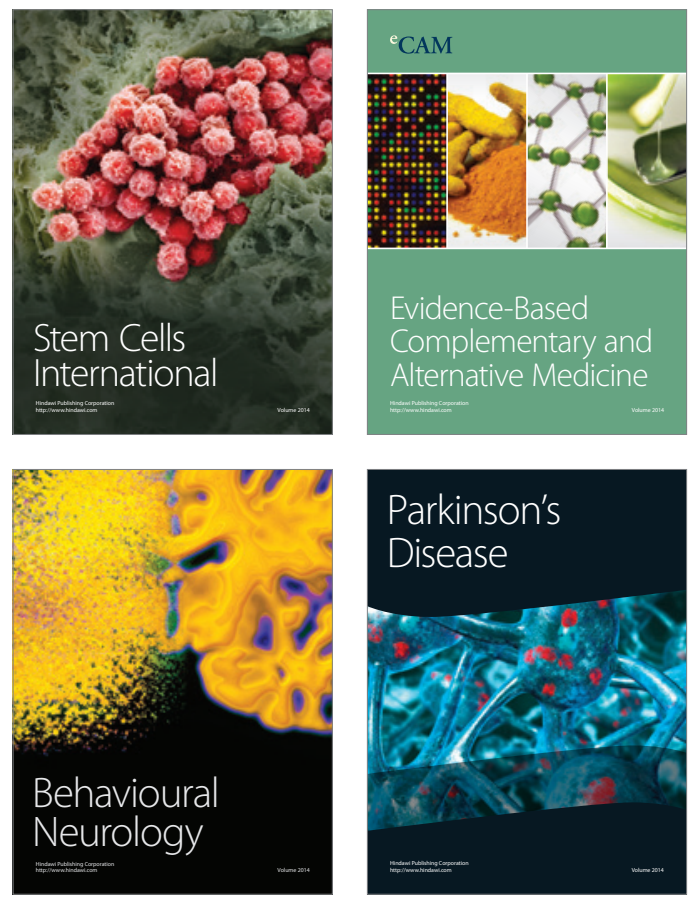
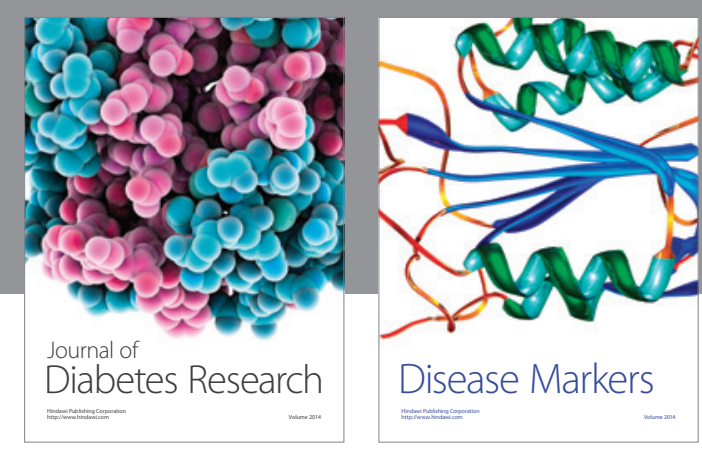

Disease Markers
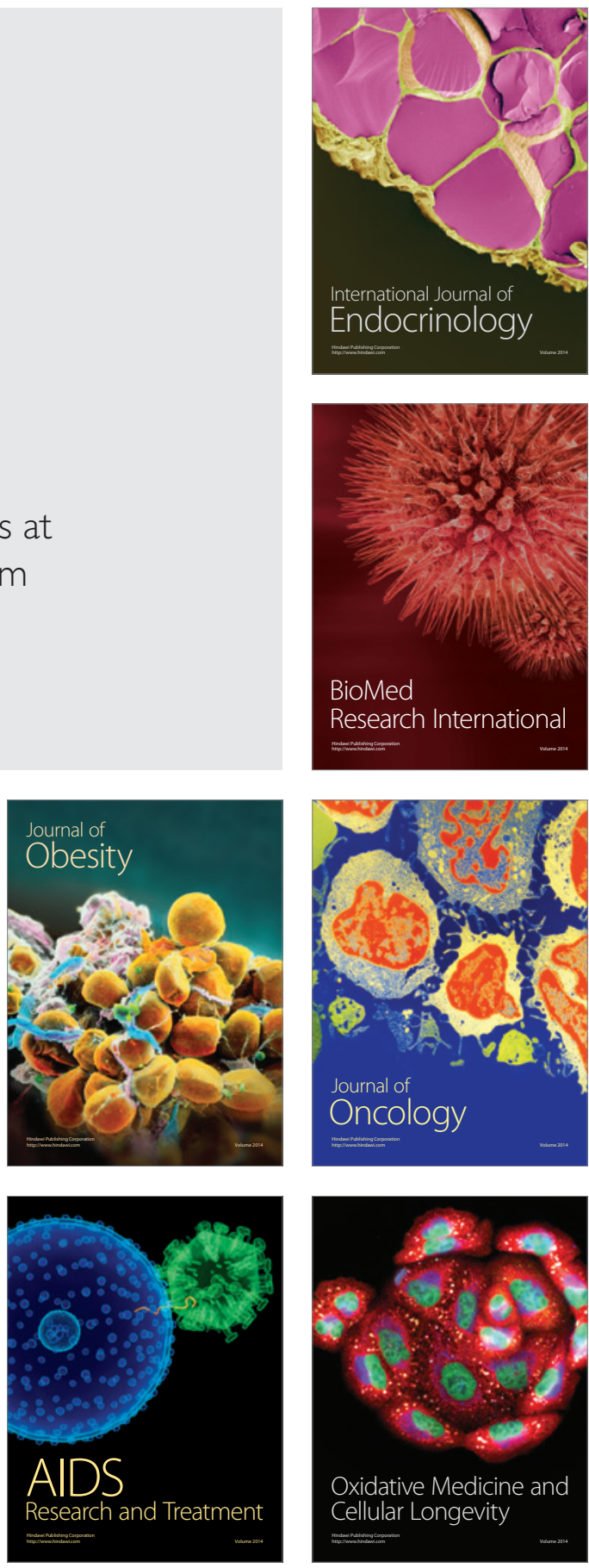